\title{
Safety and efficacy of airway stenting in patients with malignant oesophago-airway fistula
}

\author{
Janusz R. Włodarczyk, Jarosław Kużdżał \\ Department of Thoracic and Surgical Oncology, Jagiellonian University Collegium Medicum, John Paul II Hospital, Cracow, Poland \\ Contributions: (I) Conception and design: JR Włodarczyk; (II) Administrative support: J Kużdżał; (III) Provision of study materials or patients: All \\ authors; (IV) Collection and assembly of data: All authors; (V) Data analysis and interpretation: All authors; (VI) Manuscript writing: All authors; (VII) \\ Final approval of manuscript: All authors. \\ Correspondence to: Janusz R. Włodarczyk, MD, PhD. Department of Thoracic Surgery, John Paul II Hospital, ul Pradnicka 80, 31-202 Cracow, \\ Poland. Email: jr.wlodarczyk@gmail.com.
}

\begin{abstract}
Background: Close anatomical relationships between the oesophagus and the bronchial tree can lead to the formation of oesophageal fistula particularly in patients with advanced lung or oesophageal carcinoma. Stenting is a most often used treatment in such patients, but data regarding the relative value of unilateral (US) $v s$. double stenting (DS) are scarce.

Methods: Retrospective analysis of hospital records of patients with oesophageal fistula who underwent stenting between 2008 and 2016. In those in whom airway stenosis was $>30 \%$, double stenting (oesophagus and bronchial tree) was performed, whereas in those with lesser airway stenosis unilateral stenting (i.e., oesophagus only) was performed. In all patients, the degree of dysphagia, the degree of dyspnoea and the quality of life were assessed before and after the stenting.

Results: There were 46 patients, analysed, including 26 who underwent DS and 20 patients who underwent US. Both, DS and US resulted in significant improvement of dysphagia (2.72 vs. 1.2, $\mathrm{P}=0.0001$ and 2.65 vs. 1.0, $\mathrm{P}=0.0001)$, dyspnoea (2.89 vs. $0.34, \mathrm{P}=0.0001$ and 1.71 vs. $0.09, \mathrm{P}=0.0001)$ and performance score (53.2 vs. $66.3, \mathrm{P}=0.0001$ and 54.3 vs. $62.38, \mathrm{P}=0.0001)$. Neither fistula type, nor stenting method, weight loss and gain, and $\mathrm{BMI}$, had an effect on survival $(\mathrm{P}=0.34)$. Disease progression and recurrence of fistula requiring reintervention occurred in 9 patients $(19.5 \%)$.

Conclusions: Double and unilateral stenting is an effective measure to alleviate dysphagia and dyspnoea in patients treated with malignant oesophageal fistula. In those with airway stenosis of $\leq 30 \%$, stenting of the oesophagus only, instead of DS, is a safe method of treatment.
\end{abstract}

Keywords: Oesophageal cancer; lung cancer; fistula

Submitted Nov 02, 2017. Accepted for publication Apr 16, 2018.

doi: $10.21037 /$ jtd.2018.05.19

View this article at: http://dx.doi.org/10.21037/jtd.2018.05.19

\section{Introduction}

Oesophageal mediastinal fistula or oesophago-airway fistula (OAF) is a life-threatening complication of unresectable oesophageal or lung cancer, and requires prompt palliative treatment. In this setting, stenting is a procedure of choice. The incidence of oesophago-airway fistula in the course of inoperable oesophageal carcinoma increased over the last 30 years to above $10 \%$, due to wider uses of advanced treatment such as chemotherapy, chemo-radiotherapy or stenting procedures (1). This type of palliative treatment aims at improving patients' comfort, preventing septic complications in the form of severe respiratory and mediastinal infections and usually enables oral nutrition. In the published literature, there is only one paper comparing unilateral stenting (oesophageal or airway only) with double stenting (both: the oesophagus and the airway). In this study, we analyse our experience with both these methods. 


\section{Methods}

\section{Clinical characteristics}

This retrospective study included data for a consecutive group of patients with OAF treated in one institution between 2008 and 2016. Due to the character of the study, i.e. retrospective analysis of hospital records, the approval of the Ethical Committee was waived. Patients received simultaneous double stenting of the oesophagus and airway or only unilateral stenting of the oesophagus. Patients with the Karnofsky score $<40$, and patients with the oesophageal mediastinal fistula were excluded from the study group (2). Also, patients with involvement of the oesophagus $<3 \mathrm{~cm}$ from the upper esophageal sphincter and those without stenosis of the bronchial tree were excluded from the study. The characteristics of the group studied are presented in Table 1.

The patients were divided into two groups, according to the treatment received:

* Double stenting (DS) group-patients who underwent stenting of the oesophagus and the airway;

* Unilateral stenting (US) group-patients who underwent stenting of the oesophagus only.

The preoperative work-up included a chest radiogram, computerized tomography, esophagoscopy, and bronchoscopy. Cancer stage was assessed according to the 7th revision of the TNM classification (3).

Mean degree of dysphagia and mean degree of dyspnoea before and after the stenting procedure were assessed according to a four-grade scale (4):

* 0—no dysphagia;

* 1-able to swallow semi-liquid food;

* 2-able to swallow liquids;

* 3-unable to swallow liquids and saliva.

Degree of stenosis of bronchial lumen and the degree of dyspnoea were assessed according to the original, fourgrade scale (5):

* Stenosis of the bronchial lumen $<30 \%$, no dyspnoea;

* Stenosis of the bronchial lumen 30-50\%, dyspnoea on exercise;

* Stenosis of the bronchial lumen 50-70\%, dyspnoea on short-distance walk;

* Stenosis of the bronchial lumen $>70 \%$, dyspnoea on rest.

Patients with oesophageal fistula were classified according to the original classification depending on the fistula location (5):

* Type I-oesophageal-mediastinal fistula, without penetration to the bronchial tree;

* Type II-oesophageal fistula penetrating to the trachea;

* Type III-oesophageal fistula penetrating to the carina and/or main bronchus/bronchi.

Criteria for stenting procedure were as follows:

(I) Double stenting:

* Patients with unresectable oesophageal carcinoma with the fistula penetrating to the airway with bronchial tree stenosis $>30 \%$, assessed using CT and bronchoscopy;

(II) Unilateral (oesophageal) stenting:

* Patients with fistula penetrating to the airway, with airway stenosis $\leq 30 \%$;

- Lack of patient's consent for double stenting.

Patients with type I fistula were excluded from the study group.

\section{Intervention}

The airway patency was restored mechanically, under general anaesthesia, with the use of rigid bronchoscopes of 6.5, 7.5 and $8.5 \mathrm{~mm}$ diameters (Karl Storz, Tuttlingen, Germany), with argon plasma coagulation (APC, Covidien, Minneapolis, USA) or laser treatment (MY 40 1.3, KLS Martin GmbH \& Co. KG, Freiburg, Germany). Silicone Y stents (Demed, Mikołów, Poland) and covered SEMS (Ultraflex Boston Scientific Natick, MA, USA) were used (Figure 1A). The Y-type stents were implanted with the use of Freitag forceps according to the method described earlier, whereas the self-expandable bronchial stents were placed after bronchial dilatation under bronchoscopic control $(6,7)$.

Oesophageal stenting was performed under general anaesthesia. The location of stenosis and the distance from the upper oesophageal sphincter were endoscopically identified and then the dilatation was performed with the use of Savary-Gilliard dilators (Cook Medical, Bloomington, USA), up to the size of 8-10 Fr. After the dilatation, the length of involved oesophageal segment was assessed using a standard Olympus series 180 endoscope (Olympus Medical Systems Corporation, Tokyo, Japan), then a guidewire was inserted and the oesophageal stent was introduced over it. The size of the stent was selected to cover the fistula and a 3-4 cm margin of oesophageal wall above and below it. Partially covered Ultraflex SEMS (Boston Scientific, Natick, USA) were used (Figure $1 B$ and Figure 2).

Percutaneous endoscopic gastrostomy (PEG) was 

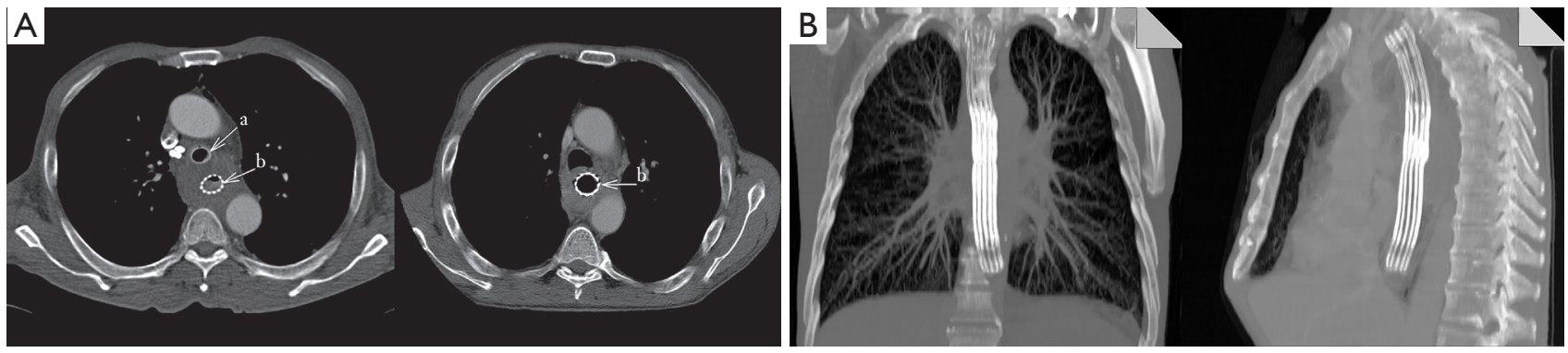

Figure 1 Multiplanar reconstructions of CT scans after esophageal and airway stenting. (A) Multiplanar reconstructions of (a, arrow) silicone Y-prosthesis and (b, arrow) esophageal prosthesis; (B) one-sided stenting (three implanted stents into one stent).

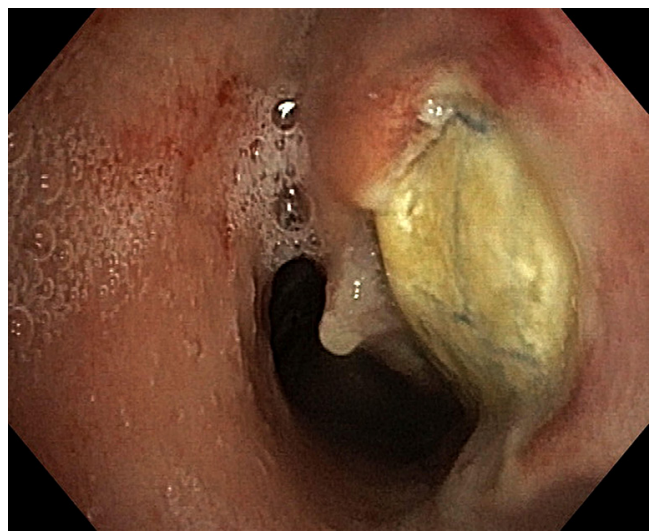

Figure 2 Bronchoscopic view of fistula in the left main bronchus fully covered after oesophageal stenting.

performed according to the technique described elsewhere, after restoration of patency of the oesophagus (8).

Following the stenting procedure, chest $\mathrm{X}$-ray was performed. On the first day after stenting the dyspnoea and dysphagia were assessed. Semi-liquid diet was allowed and patients received detailed information regarding the regimen of oral nutrition whilst stented.

In the postoperative period, patients underwent a medical check-up on the first day after the procedure and then every 30 days. If necessary, additional follow-up visits were planned after phone confirmation. The follow-up included chest X-ray, esophagoscopy, bronchoscopy and, if necessary, computed tomography. During a follow-up visit patient's overall condition, performance status, dyspnoea and dysphagia were assessed.

\section{Statistical analysis}

Statistical analysis was performed using the STATISTICA
10 PL software package (StatSoft, Tulsa Oklahoma, USA). Differences between two groups were tested with GehanWilcoxon's, Kruskal-Wallis and Mann-Whitney tests. Log-rank, Chi-square, Fisher's tests and odds ratio were calculated to compare groups for complications and reinterventions. Survival time was calculated using KaplanMeier method. $\mathrm{P}<0.05$ was considered as statistically significant.

\section{Results}

Between 2008 and 2016, 46 patients with oesophageal fistula underwent stenting. In 26 of them, in whom airway stenosis exceeded 30\%, DS was performed, whereas in 20 patients with lesser airway stenosis US was performed.

\section{Results of stenting}

The DS group included 26 patients with squamous cell oesophageal cancer. In all but one of them the procedure was performed electively. Mean body weight loss was $10.6 \mathrm{~kg}$ (range, $0-30 \mathrm{~kg}$ ). In the 26 patients with primary oesophageal cancer the mean length of involved oesophageal segment was $5.87 \mathrm{~cm}$ (range, 4-8 cm). Type II fistula was detected in $10(21.73 \%)$ patients, and type III in $16(34.78 \%)$ patients (Table 1). Mean degree of airway stenosis was $42.6 \%$ (range, $40-85 \%$ ).

Oesophageal stenting with the use of partially-covered SEMS was performed in all patients. For the bronchial tree, the silicone Y-stents were implanted in 20 (43.47\%) patients, covered tracheal SEMS were used in 10 (21.73\%). In 6 (13.04\%) patients PEG was additionally placed.

Following the DS, appropriate patency of bronchial tree was restored and complete fistula coverage was obtained in all patients. Oral feeding was restored in all patients and 
Table 1 Clinical and demographic data of the patients

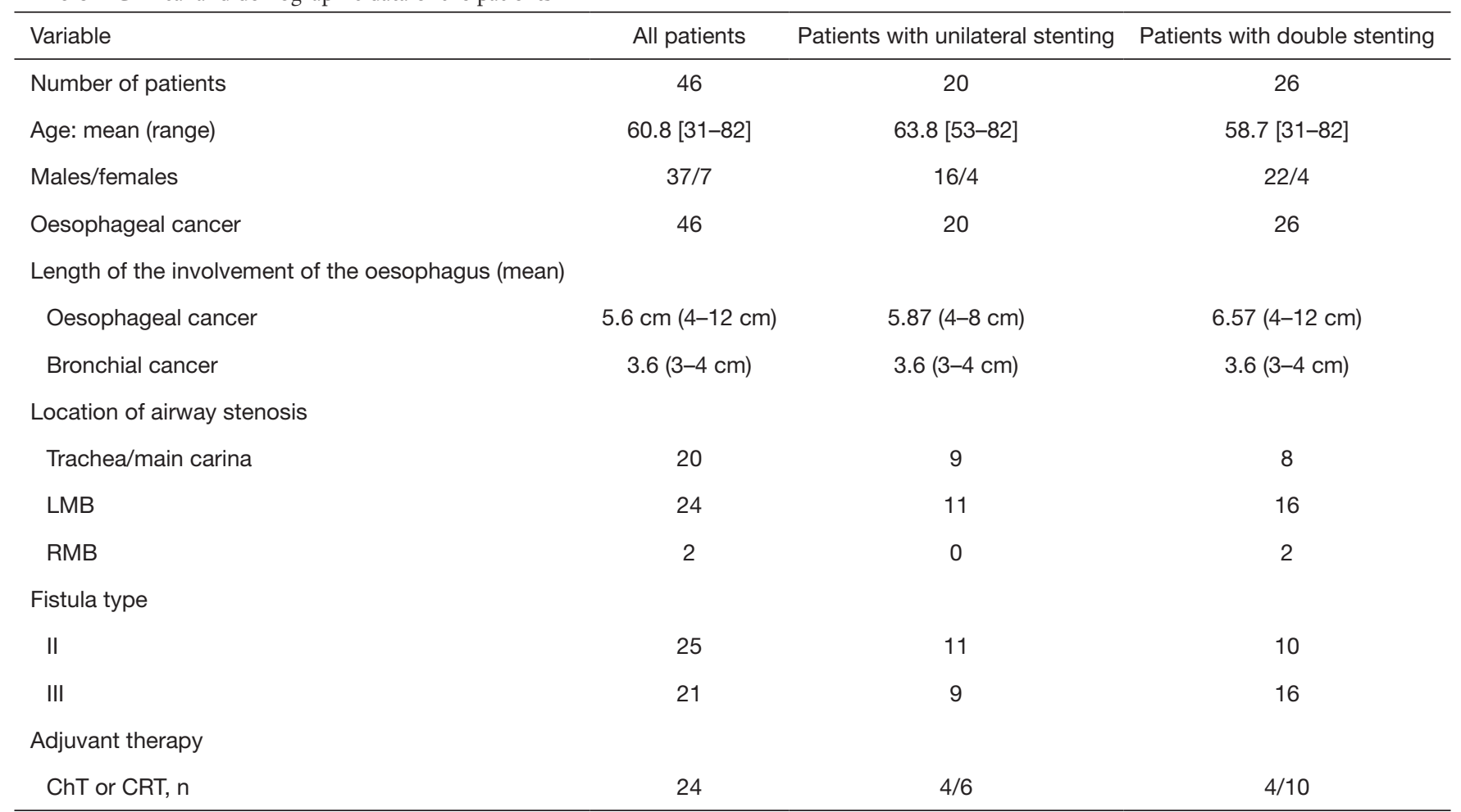

LMB, left main bronchus; RMB, right main bronchus; NSCLC, non-small cell lung cancer; SCLC, small cell lung cancer, ChT, chemotherapy; CRT, chemoradiotherapy.

significant improvement of dysphagia was noted (2.72 vs. $1.2, \mathrm{P}=0.0001)$. Similarly, dyspnoea improved significantly (2.89 vs. $0.34, \mathrm{P}=0.0001$ ) as well as performance score $(53.2$ vs. 66.3, $\mathrm{P}=0.0001$ ) (Table 2). Mean survival in the $\mathrm{DS}$ group was 65.3 days (range, 3-187 days) (Figure 1). Details of the results of DS are shown in Table 2.

The US group included 20 patients with oesophageal cancer. Mean body weight loss in this group was $8.54 \mathrm{~kg}$ (range, 0-20 kg), mean length of involved oesophageal segment was $5.6 \mathrm{~cm}$ (range, $4-12 \mathrm{~cm}$ ), and mean bronchial tree stenosis was $25 \%$ (range, $10-30 \%$ ), the rate significantly lower than in the DS group $(\mathrm{P}=0.0001)$. Type II fistula with airway compressed diagnosed in 11 (23.91\%) patients, type III—in $9(19.56 \%)$ patients. All procedures in this group were performed electively using partially covered SEMS.

After the stenting procedure, the patency of the oesophagus was restored in all the patients, they resumed oral diet and dysphagia score improved significantly: $2.65 \mathrm{vs}$. 1.0, $(\mathrm{P}=0.0001)$. Following stenting, body weight improved significantly: $-8.54 v s .+0.9, \mathrm{P}=0.0089$. In 3 patients $(11.5 \%)$ additionally PEG was performed without perioperative complications. Mean survival in the US group was 68.9 days (range, 30-200 days) (Figure 1). Details of the results of US are shown in Table 3.

In the whole cohort of 46 patients the mean follow-up was 73.8 days (range, 3-329 days).

Comparison of DS and US has shown the following results:

There were no significant differences between the DS group and the US group regarding:

* Mean dysphagia score before (2.72 and 2.65, respectively) and after stenting (1.2 and 1.0, respectively) $(\mathrm{P}=0.74)$;

* Mean body weight loss before (11.22 and 8.54, respectively) and after stenting $(+1.83$ and +0.9 , respectively) $(\mathrm{P}=0.85)$;

- BMI before (18.6 and 19.84, respectively) and after stenting (19.98 and 20.17) $(\mathrm{P}=0.54)$;

- Karnofsky score before (53.2 and 54.3, respectively) and after stenting (66.3 and 62.38, respectively) $(\mathrm{P}=0.79)$; 
Table 2 Results of patients with double stenting

\begin{tabular}{|c|c|c|c|}
\hline Variable & Before stenting & After stenting & $P$ value \\
\hline Mean degree of dysphagia (range) & 2.72 (0 to 3$)$ & $1.2(0$ to 3$)$ & 0.0001 \\
\hline Mean weight gain/loss (kg) & -11.22 (3 to 30$)$ & $1.83(-2$ to 5$)$ & 0.0087 \\
\hline Mean BMI (range) & $18.6(16.41-28.68)$ & 19.98 (16.71 to 28.68$)$ & 0.025 \\
\hline
\end{tabular}

BMI, body mass index.

Table 3 Results of patients with one-sided stenting

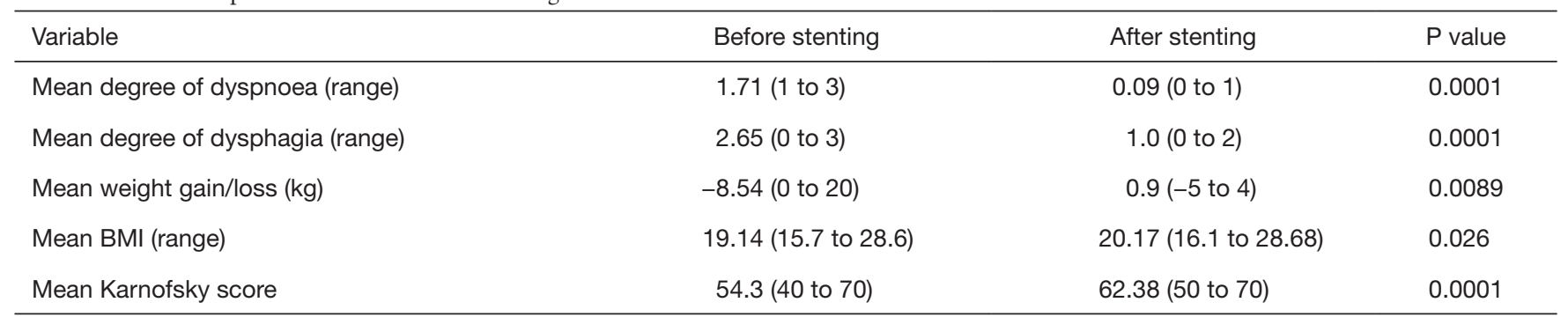

BMI, body mass index.

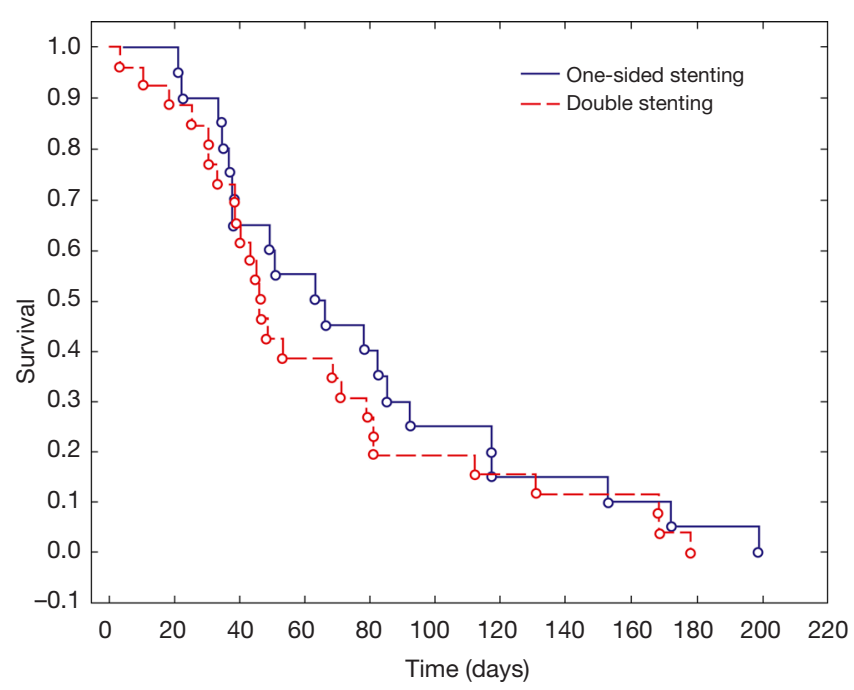

Figure 3 Kaplan-Meier curve of survival of patients with double (DS) and one-sided stenting (US).

* Overall survival time ( 65.3 vs. 68.9 respectively) $(\mathrm{P}=0.64)$ (Figure 3);

* Survival time according to the fistula type (range, 3-187 and 30-200 days respectively) ( $\mathrm{P}=0.79)$.

There was a significant difference between the DS group and the US group regarding severity of airway stenosis
(42.6\% vs. $25 \%$ respectively) $(\mathrm{P}=0.0001)$.

* Mean dyspnoea score before (2.83 vs. 1.7 respectively) $(\mathrm{P}=0.0003)$ and after stenting $(0.34$ and 0.09 , respectively) $(\mathrm{P}=0.0028)$.

\section{Complications}

Minor adverse effects occurred in $41(89.1 \%)$ patients. Immediately after the procedure, $21(45.6 \%)$ patients experienced pain or discomfort in the chest, lasting for 1-4 days and requiring analgesics, including 14 (30.43\%) patients in DS group versus 7 (15.21\%) in the US group. In four $(8.7 \%)$ patients, including $3(6.52 \%)$ in DS and 1 $(2.17 \%)$ in US group, complete expansion of oesophageal stent was delayed to 48 hours; no intervention was needed in those patients. Four (8.7\%) patients in DS group experienced transient dysphagia with chest discomfort and bronchoscopy was required in $12(26 \%)$ patients, including $10(21.7 \%)$ in DS and 2 (4.2\%) in US group, due to bronchial secretions retention. The risk of complications was significantly higher in the DS group $(\mathrm{P}=0.029, \mathrm{OR}=5.63)$.

Severe complications occurred in 11 patients (23.91\%). In 1 patient $(3.8 \%)$ in the DS group massive fatal haemorrhage occurred on the third postoperative day. In another patient in this group during the restoration 
Table 4 Re-interventions

\begin{tabular}{|c|c|c|c|c|c|c|c|}
\hline $\begin{array}{l}\text { Sex and } \\
\text { age of the } \\
\text { patient }\end{array}$ & $\begin{array}{l}\text { Fistula } \\
\text { type }\end{array}$ & Stenting & Complication & $\begin{array}{l}\text { Time from the stenting } \\
\text { procedure to the } \\
\text { occurrence of } \\
\text { complication (days) }\end{array}$ & Applied treatment & $\begin{array}{l}\text { Complication } \\
\text { after the } \\
\text { re-intervention }\end{array}$ & $\begin{array}{c}\text { Survival after the } \\
\text { re-intervention } \\
\text { (days) }\end{array}$ \\
\hline M, 49 & I & DS & $\begin{array}{l}\text { Stent migration, } \\
\text { fistula to the trachea }\end{array}$ & 53 & $\begin{array}{l}\text { Re-stenting of the } \\
\text { oesophagus }\end{array}$ & No & 75 \\
\hline$M, 55$ & III & DS & $\begin{array}{l}\text { Reopening of the fistula, } \\
\text { stent migration }\end{array}$ & 28 & Re-stenting of the airway & No & 5 \\
\hline M, 81 & III & DS & $\begin{array}{l}\text { Reopening of the fistula, } \\
\text { stent migration }\end{array}$ & 20 and 14 & Re-stenting of the airway & Pneumothorax & 28 \\
\hline M, 56 & $\|$ & US & $\begin{array}{l}\text { Reopening of the fistula, } \\
\text { stent migration }\end{array}$ & 54 & $\begin{array}{l}\text { Re-stenting of the } \\
\text { oesophagus }\end{array}$ & No & 45 \\
\hline M, 68 & ॥ & US & $\begin{array}{l}\text { Reopening of the fistula, } \\
\text { stent migration }\end{array}$ & 61 & $\begin{array}{l}\text { Re-stenting of the } \\
\text { oesophagus }\end{array}$ & No & 37 \\
\hline M, 72 & III & US & $\begin{array}{l}\text { Reopening of the fistula, } \\
\text { stent migration }\end{array}$ & 49 & $\begin{array}{l}\text { Re-stenting of the } \\
\text { oesophagus }\end{array}$ & No & 41 \\
\hline
\end{tabular}

US, unilateral stenting; DS, double stenting.

of patency of bronchial tree before stenting massive haemorrhage occurred. The silicone Y-stent was successfully inserted. The patient required mechanical ventilation for 10 hours, but recovered and was discharged.

Recurrence of the fistula occurred in $9(19.56 \%)$ patients: $6(13 \%)$ in the DS group and in $3(6.5 \%)$ in the US group $(\mathrm{P}=0.13)$. In all of them the re-opening of fistula was associated with stent migration. In 3 out of 6 patients after DS partial migration of SEMS was observed, in 2complete migration of SEMS was noted and in 1 patient migration of a Y-stent occurred. In 2 out of 3 patients after US partial migration of SEMS was observed, and in 1complete migration of SEMS was noted.

\section{Re-interventions}

In the DS group, 6 (13\%) patients required re-intervention due to the progression of the tumour or because of stentingrelated complications. In the US group, re-intervention was needed in $3(6.5 \%)$ patients because of a recurrence of the fistula or stent migration. There was not a significant difference between the DS group and the US group regarding to re-interventions $(\mathrm{P}=0.09)$.

Details of the re-interventions are summarized in Table 4.

After the stenting procedure, 14 (55\%) patients in the DS group and $10(50 \%)$ patients in the US group received adjuvant chemotherapy and/or radiation therapy but no effects on survival were detected $(\mathrm{P}=0.31)$.

\section{Discussion}

Oesophago-airway fistula is one of the most severe complications of unresectable oesophageal cancer, but also tumours with secondary infiltration of the oesophagus, i.e., lung cancer and, rarely, mediastinal tumours. Reportedly, fistula occurs in $15 \%$ of patients with oesophageal cancer and in $1 \%$ of patients with lung cancer. The most frequent location of fistula is trachea (52-57\%), followed by 
bronchi (37-40\%) and lung parenchyma (3-11\%) (9-11). Risk factors for the OAF formation include locally advanced tumour, the application of radiation therapy and chemotherapy, and stenting procedures during the course of malignant dysphagia.

Patients with OAF are generally characterized by poor general condition, malnutrition, increasing dyspnoea, recurrent aspiration pneumonia and progressive cachexia. The aim of the palliative treatment in these patients is restoration of patency of the oesophagus and airway and sealing of the fistula preventing the aspiration of oesophageal content to the bronchial tree. Although the NCCN guidelines are relatively vague on the topic and proposed double stenting for malignant OAFs, than the ESGE clearly recommends esophageal self-expanding metallic stent insertion as the first line, with double stenting mentioned as worth considering if the esophageal SEMS does not seal the fistula $(12,13)$.

Successful management of OAF requires complete fistula coverage by the oesophageal stent and, in case of airway stenosis, double stenting of the airway and the oesophagus. According to the literature, the effectiveness of such management is between $75 \%$ and $100 \%$ (14-21). Our results, showing a technical success rate of $98 \%$, are consistent with the published data.

Partially covered or fully covered SEMS are recommended in case of OAF. It should be noted, that in case of partial obstruction or compression of the airway, SEMS expansion may exacerbate its compression to the degree of impeding suffocation. As restoration of airway patency may be technically difficult in such situation, tracheobronchial Y-stent should be inserted prior to the oesophageal stenting. The use of silicone Y-stents is recommended by most authors $(6,7,12,22)$.

Oesophageal SEMS are characterized by simple implantation as well as a relatively low migration and obstruction rate. Implantation of the silicone Y-stents is technically more difficult, but these stents have very low migration rate and are well tolerated by patients, even in a long-term follow-up $(6,22)$. Proper stent expansion is crucial in patients with OAF. Wang et al. describe the 'funnel phenomenon' in case of incomplete expansion of the proximal end of the SEMS, resulting in the formation of an empty space between the stent and the oesophageal wall, making the stenting procedure ineffective. Attempts to dilate the stent, or additional stenting procedure are usually ineffective (23).

The most common complications after the stenting procedure include stent migration and obstruction. Stent migration occurs in $4-15 \%$ of patients (20-27). In our group this occurred in $9(19.5 \%)$ patients, which is consistent with the literature data. Ke et al. consider double stenting as associated with high rate of oesophageal stent migration (27).

Freitag et al. compared the effectiveness of double stenting (oesophageal and airway) and unilateral stenting (airway only) and concluded that survival was significantly longer in patients in the double stenting group-110 vs. 24 days (14). In should be stressed, however, that similarly to our study, the clinical characteristics of patients in DS and US group differed, and this selection bias makes any comparison disputable. Shin et al. demonstrated that among 61 patients who underwent unilateral stenting the fistula was not completely covered in 12 patients and fistula recurrence occurred in 17 patients (26).

Recurrence rate of the $\mathrm{OAF}$ is reported in a wide range $(0-35 \%)$ and its risk factors are not well known. They can be associated with disease progression, but also with pressure necrosis and erosion on the oesophageal and airway wall after double stenting due to significant and competing radial force (24-26). For this reason, DS should be avoided if is possible. For recurrent OAF, double stenting may be more effective that unilateral stenting. Rodriguez et al. also confirm the advantage of double stenting over unilateral stenting (16). In the present study, partially covered SEMS were used in all patients and the survivals were not statistically significantly different depending on the way of treatment (DS or US). Improvement of the performance score after stenting was also similar in both groups. It should be noted that the rate of re-interventions was $19.56 \%$, and was associated with disease progression, fistula recurrence and stent migration.

In our group, all re-interventions were successfully performed and the improvement of patients' quality of life was achieved. It suggests the need of active management of these patients, despite the obvious palliative setting. The most difficult problem is inevitable disease progression and poor general condition of patients, which can hinder the effective re-intervention. The re-interventions rate was not significantly different between both groups, and the patients with DS had greater progression and recurrence rate of the fistula, higher rate of complications and higher rate of re-interventions. Our results suggest that US is a safe and effective treatment in patients in whom the airway stenosis does not exceed $30 \%$ of the lumen.

Depending on patient's clinical status, body weight and BMI loss, and the feasibility of maintaining adequate 
oral feeding, PEG should be considered. In our group, a statistically significant increase in body weight was observed after stenting, but there was no significant difference between the DS and the US group.

Literature data regarding benefit from adjuvant chemotherapy and/or radiation therapy are conflicting. Some authors report a positive effect on closure of OAF and survival $(28,29)$. Hamai et al. and Herth et al. reported longer survival in patients who underwent adjuvant therapy $(30,31)$. In our study adjuvant therapy after stenting did not influence survival ratio among the patients from groups DS and US, but the number of patients in these subgroups were too small to allow for definitive conclusion in this regard.

In the published literature, there is lack of data on the comparison of DS and US and the results of these procedures in patients with malignant oesophageal fistula, which is obvious given the different patients' populations. Our results demonstrate the effectiveness of US in patients with minor airway stenosis, with low rate of complications. Double stenting may be an alternative to US in patients with bronchial tree stenosis exceeding $30 \%$. While considering double stenting procedure, a higher rate of long-term re-interventions should be taken into account.

The limitations of the study include its retrospective nature and relatively small number of patients, which is due to the single-centre data collection. However, most analyses of rare clinical problems, like OAF, tend to include small series of patients.

\section{Acknowledgements}

None.

\section{Footnote}

Conflicts of Interest: The authors have no conflicts of interest to declare

Ethical Statement: Due to the character of the study, i.e., retrospective analysis of hospital records, the approval of the Ethical Committee was waived.

\section{References}

1. Hürtgen M, Herber SC. Treatment of malignant tracheoesophageal fistula. Thorac Surg Clin 2014;24:117-27.

2. Karnofsky DA, Burchenal JH. The clinical evaluation of chemoterapeutic agents in cancer. In: McLeod CM. editor. Evaluation of chemioterapeutic agents. Columbia Press, 1949:196.

3. Sobin LH, Gospodarowicz M, Wittekind C. UICCInternational Union Against Cancer. TNM classification of malignant tumours. New York: J Wiley and Sons, 2010.

4. Blazeby JM, Williams MH, Brookes ST, et al. Quality of life measurement in patients with oesophageal cancer. Gut 1995;37:505-8.

5. Włodarczyk J, Kużdżał J. Double stenting for malignant oesophago-respiratory fistula. Wideochir Inne Tech Maloinwazyjne 2016;11:214-21.

6. Dumon JF. A dedicated tracheobronchial stent. Chest 1990;97:328-32.

7. Stephens KE Jr, Wood DE. Bronchoscopic management of central airway obstruction. J Thorac Cardiovasc Surg 2000;119:289-96.

8. Gauderer MW, Ponsky JL, Izant RJ Jr. Gastrostomy without laparotomy: a percutaneous endoscopic technique. J Pediatr Surg 1980;15:872-5.

9. Martini N, Goodner JT, D'Angio GJ, et al. Tracheoesophageal fistula due to cancer. J Thorac Cardiovasc Surg 1970;59:319-24.

10. Angorn IB. Intubation in the treatment of carcinoma of the esophagus. World J Surg 1981;5:535-41.

11. Duranceau A, Jamieson GG. Malignant tracheoesophageal fistula. Ann Thorac Surg 1984;37:346-54.

12. Spaander MC, Baron TH, Siersema PD, et al. Esophageal stenting for benign and malignant disease: ESGE Clinical Guideline. Endoscopy 2016;48:939-48.

13. National Comprehensive Cancer Network Guidelines for the treatment of esophageal cancer 2015. Available online: www.nccn.org/professionals/physcian-glsf-guidelines. asp\#site. 2015

14. Freitag L, Tekolf E, Steveling H, et al. Management of malignant esophagotracheal fistulas with airway stenting and double stenting. Chest 1996;110:1155-60.

15. Colt HG, Meric B, Dumon JF. Double stents for carcinoma of the esophagus invading the tracheo-bronchial tree. Gastrointest Endosc 1992;38:485-9.

16. Rodriguez AN, Diaz-Jimenez JP. Malignant respiratorydigestive fistulas. Curr Opin Pulm Med 2010;16:329-33.

17. Hu Y, Zhao YF, Chen LQ, et al. Comparative study of different treatments for malignant tracheoesophageal/ bronchoesophageal fistulae. Dis Esophagus 2009;22:526-31.

18. Van Heel NC, Haringsma J, Spaander MC, et al. Esophageal stents for the palliation of malignant dysphagia 
and fistula recurrence after esophagectomy. Gastrointest Endosc 2010;72:249-54.

19. Bergquist H, Wenger U, Johnsson E, et al. Stent insertion or endoluminal brachytherapy as palliation of patients with advanced cancer of the esophagus and gastroesophageal junction. Results of a randomized, controlled clinical trial. Dis Esophagus 2005;18:131-9.

20. Chen YH, Li SH, Chiu YC, et al. Comparative study of esophageal stent and feeding gastrostomy/jejunostomy for tracheoesophageal fistula caused by esophageal squamous cell carcinoma. PloS One 2012;7:e42766.

21. Sharma P, Kozarek R. Practice Parameters Committee of American College of Gastroenterology. Role of esophageal stents in benign and malignant diseases. Am J Gastroenterol 2010;105:258-73.

22. Mijazawa T, Yamakido M, Ikeda S, et al. Implantation of ultraflex nitinol stents in malignant tracheobronchial stenoses. Chest 2000;118:959-65.

23. Wang MQ, Sze DY, Wang ZP, et al. Delayed complications after esophageal stent placement for treatment of malignant esophageal obstructions and esophagorespiratory fistulas. J Vasc Interv Radiol 2001;12:465-74.

24. Saxon RR, Barton RE, Katon RM, et al. Treatment of malignant esophageal obstructions with covered metallic

Cite this article as: Włodarczyk JR, Kużdżał J. Safety and efficacy of airway stenting in patients with malignant oesophago-airway fistula. J Thorac Dis 2018;10(5):2731-2739. doi: $10.21037 /$ jtd.2018.05.19
Z stents: long-term results in 52 patients. J Vasc Interv Radiol 1995;6:747-54.

25. Saxon RR, Morrison KE, Lakin PC, et al. Malignant esophageal obstruction and esophagorespiratory fistula: palliation with a polyethylene-covered Z-stent. Radiology 1997;202:349-54.

26. Shin JH, Song HY, Ko GY, et al. Esophagorespiratory fistula: long-term results of palliative treatment with covered expandable metallic stents in 61 patients. Radiology 2004;232:252-9.

27. Ke M, Wu X, Zeng J. The treatment strategy for tracheoesophageal fistula. J Thorac Dis 2015;7:S389-97.

28. Gore E, Currey A, Choong N. Tracheoesophageal fistula associated with bevacizumab 21 months after completion of radiation therapy. J Thorac Oncol 2009;4:1590-1.

29. Park JY, Shin JH, Song HY, et al. Airway complications after covered stent placement for malignant esophageal stricture: special reference to radiation therapy. AJR AM J Roentgenol 2012;198:453-9.

30. Hamai Y, Hihara J, Emi M, et al. Airway stenting or malignant respiratory complications in esophageal cancer. Anticancer Res 2012;32:1785-90.

31. Herth FJ, Peter S, Baty F, et al. Combined airway and oesophageal stenting in malignant airway-oesophageal fistulas: a prospective study. Eur Respir J 2010;36:1370-4. 